\title{
A LITERATURA QUE SE ENSINA NO 20 CICLO DO BÁSICO PORTUGUÊS: DESAJUSTAMENTOS E REDUPLICAÇÕES
}

\author{
Pedro Balaus Custódio \\ Doutor em Didática da Literatura pela Universidade de Coimbra \\ Professor Coordenador da Escola Superior de Educação de Coimbra \\ balaus@gmail.com
}

\section{RESUMO}

De acordo com o atual programa e metas curriculares de Português para o 2 o ciclo do ensino básico de Portugal, alguns dos objetivos nucleares passam por desenvolver nos alunos a capacidade de leitura de textos de diferentes temas e géneros. Esses enunciados devem ser de expressão não literária, mas também literária. São sobretudo estes que permitirão aos jovens inaugurar um conhecimento fundamentado e sólido da literatura, bem como possibilitar a construção de conhecimentos de e sobre o fenómeno literário, o desenvolvimento do gosto de ler e, ainda, a valorização da literatura enquanto património. Por entre esses múltiplos objetivos, destaca-se ainda o da apreciação crítica e da dimensão estética dos textos, quer portugueses, quer estrangeiros. Para cumprir esses objetivos no domínio da educação literária, as autoras propõem uma lista de oito obras e de textos para leitura anual. Estes títulos deverão ser posteriormente complementados com as sugestões contidas no Plano Nacional de Leitura (PNL). Assim, em primeiro lugar, pretendemos pôr em evidência algumas práticas resultantes da aplicação desse programa de Português, desde 2015 até o presente, e compreender de que modo é que essas orientações se traduzem na variedade das leituras realizadas pelos alunos, e não na sua reduplicação. Em segundo lugar, avaliar até que ponto essas escoIhas são realizadas de acordo com a faixa etária e maturidade leitora dos destinatários, os seus horizontes de expetativa e gostos pessoais e se, na esfera do texto literário, estão isentas de reiterações ao longo do percurso escolar.

Palavras-chave: Educação literária; texto literário; didática do texto literário; Educação Básica.

\begin{abstract}
According to the current program and curricular goals of Portuguese for the 2nd cycle of primary education from Portugal, some of the core objectives are developing in students the ability to read texts of different themes and genres. These statements include non-literary, but also literary examples. These ones will allow young people to acquire a grounded and solid knowledge of literature, as well as will enable the construction of knowledge from and about the literary phenomenon, the development of the taste for reading and the appreciation of literature as a heritage. Among these multiple objectives, it is also worth highlighting the critical appraisal and a esthetic dimension of the texts, both Portuguese and foreigners. For this reason, in the field of literary education, the authors propose a list of eight works and texts for annual reading. These texts, in a small number, should be complemented with the some suggested in the National Reading Plan. Firstly, our aim is to highlight some of the practices resulting from the application of this Portuguese program from 2015 to the present, and understand how these guidelines are translated into the variety of reading exercises carried out by students, and not in its reduplication. Secondly, to access the extent to which the text choices are made according to the students' age group and readership maturity, their expectations and personal tastes, and whether or not these choices are exempt from repetitions throughout the course of their school lives, in the literary text sphere.
\end{abstract}

Palabras clave: Literary education; literary text; didactic of the literary text; Basic Education. 


\section{Do Programa de Português aos manuais escolares: os textos literários que chegam à foz}

O 2 ำ ciclo de educação básica português ( 2 CEB) é atualmente estruturado em quatro domínios de estudo: Oralidade (O); Leitura e Escrita (LE); Educação Literária (EL) e Gramática. A operacionalização do Programa está definida nas Metas Curriculares, sendo os objetivos e descritores obrigatórios em cada ano letivo, subsequentemente mobilizados, numa dinâmica espiral, sempre que se considere necessário.

Os textos literários aconselhados estão, também, contemplados no documento curricular e incluem, no 5o ano, seis poemas de Álvaro Manuel Magalhães, do livro $O$ Limpa-Palavras e outros Poemas; outros seis de Luísa Ducla Soares, de A Cavalo no Tempo; A Vida Mágica da Sementinha, de Alves Redol; O Príncipe Nabo, de llse Losa; três lendas da recolha de Gentil Marques ou, em alternativa, três contos ou lendas selecionadas por João Pedro Mésseder e Isabel Ramalhete, do volume Contos e Lendas de Portugal e do Mundo. ("A lenda do milagre das rosas", "A lenda das três Mouras encantadas", "A lenda da Batalha de Ourique", "A lenda da Serra da Estrela", "A lenda da Senhora da Nazaré", "A lenda das amendoeiras").

O Pássaro na Cabeça, de Manuel António Pina, está também incluído, assim como a Fada Oriana ou o Rapaz de Bronze, de Sophia de M. B. Andresen. A sétima sugestão incide sobre as fábulas de La Fontaine, "A Cigarra e a Formiga", "O Lobo e a Raposa”, "A Raposa e as Uvas", "A Raposa e a Cegonha", "O Leão e o Rato", "O Velho, o Rapaz e o Burro", "A Galinha dos Ovos de Oiro", "A Lebre e a Tartaruga" in Fábulas, de entre os quais se devem selecionar quatro textos para leitura. A alternativa passa pela seleção de outros quatro, desta vez das Fábulas de Esopo. A última sugestão incide sobre $A$ Viúva e $o$ Papagaio, de Virginia Woolf. 
Para o 60 ano, Rosa, minha Irmã Rosa ou Chocolate à Chuva, de Alice Vieira; ou, em alternativa, Pedro Alecrim, de António Mota.

São aconselhados ainda os textos do Romanceiro, de Almeida Garrett, "A Nau Catrineta"; "A Bela Infanta", os Contos Gregos, de António Sérgio, ou, em opção, Ulisses, de Maria Alberta Menéres. De Manuel Alegre estão os textos As Naus de Verde Pinho e Viagem de Bartolomeu Dias, assim como Os Piratas (texto dramático), de Manuel António Pina. De Sophia de M. B. Andresen sugerem-se ainda seis poemas de Primeiro Livro de Poesia ou seis outros de autores lusófonos, bem como contos dos irmãos Grimm ou textos, em número de quatro, de Robinson Crusoé, de Daniel Defoe, Ali Babá e os Quarenta Ladrões.

Essa seleção não é, obviamente, um bastião cerrado, não só porque o Programa aconselha o constante diálogo com o acervo do PNL, mas também porque o docente pode sugerir diferentes leituras de acordo com o seu conhecimento pessoal dos textos, obras e autores. Ballester (2015, p. 121) refere esse fator, ao afirmar que "Los docentes deben ser lectores y conocer los textos con los que pretenden despertar el interés del niño por la lectura". Ora, para além das instruções programáticas, o PNL disponibiliza, pois, um largo acervo de centenas de sugestões para cada ciclo de ensino. Como notamos num estudo anterior,

há algumas questões sempre pertinentes aquando da avaliação de um manual no que toca à capacidade de promover a leitura e cativar os alunos; perguntas a que todos os manuais tentam dar a resposta mais eficaz: os textos e as atividades em torno deles promovem o gosto pela leitura? Que textos são usados para tal finalidade? As atividades apensas ao texto são cruciais para esse objetivo? Os textos são suficientemente ricos, diversificados e ecléticos? Estão adaptados aos leitores a que se destinam? O trabalho de compreensão dos textos é priorizado aquando da leitura? As leituras são excessivamente orientadas e controladas pelo 
professor? Os textos incluídos nos manuais são todos escolarizáveis? (CUSTÓDIO, 2017a, p. 57).

De facto, essas questões são de assinalável relevo porquanto sabemos que o manual escolar legitima as leituras em sala de aula (e, muitas vezes, fora dela), define o cânone textual para um determinado ano ou ciclo e, de uma forma mais ou menos precisa, acaba por determinar os textos que os alunos leem e estudam.

Como acentuaram alguns autores (DIONÍSIO, 2000; CASTRO, 1999; CABRAL, 2005), o manual escolar impõe-se ao currículo de Português, tornando-se a principal e, não raro, a única fonte de conhecimento e de trabalho para a maioria dos alunos. Há, assim, duas questões que nos afiguram pertinentes e dignas de ponderação.

A primeira, identificar quais os textos que o Programa assinala como leituras obrigatórias; a segunda, perceber de que modo os manuais plasmam essas indicações ou as enriquecem com outras que são sugeridas pelo PNL ou, se pelo contrário, evidenciam algum grau de redundância e de reduplicação entre anos ou mesmo entre ciclos.

Serão essas razões consequentes e decisivas para a qualidade das leituras e para a formação do leitor? Não é fácil dar uma resposta cabal a essa pergunta, mas estamos em crer que, pelo menos, poderão condicionar, em parte, a forma como fazemos a motivação do jovem para a leitura literária.

Como sublinhamos,

Não porque estas sejam inoperantes ou insuficientes, mas sobretudo porque muitos textos literários de grande relevo não estão, realmente, disponíveis a todos os professores. Ora porque não se encontram acessíveis editorialmente, ora porque o docente não tem tempo, oportunidade e/ou possibilidade de os coligir, comprar ou enquadrar nas aulas, ora ainda porque podem ser mesmo desconhecidos de alguns (CUSTÓDIO, 2017a, p. 58). 
Assim, e após termos elencado os textos que o Programa prescreve, importa perceber se os manuais vertem essas sugestões para as suas páginas.

A produção de manuais escolares é prolífica e apenas um extenso e demorado estudo nos permitiria aclarar de que modo estão esses instrumentos de recontextualização pedagógica a emular os textos e os autores que o Programa de Português prescreve. Como é compreensível, não nos é possível, nesse contexto, executar essa tarefa. Ela é de colossal envergadura e nos obrigaria a sinalizar todos os manuais atualmente em vigor nos $5 \circ$ e 60 anos do 2 을 CEB, de modo a concluir, com exatidão, quais os textos e os autores que chegam aos olhos desses jovens leitores. Esse trabalho, apesar de muito aliciante, não está ainda feito, não apenas pela sua extensão e complexidade, mas também por razões operacionais que se prendem com inúmeros fatores de natureza extracurricular, como é o caso da alternância significativa de manuais entre os agrupamentos.

\section{Os textos emergentes: desajustamentos e reduplicações?}

Ora, na impossibilidade de apresentar conclusões eloquentes e estatisticamente ratificadas por um estudo dessa natureza, optamos por selecionar apenas dois dos manuais que têm uma implementação expressiva no mercado editorial para esses dois anos do 2o ciclo da educação básica.

Para tal, escolhemos dois livros, de diferentes editoras e atualmente em vigor. Assim, ambos os manuais do 5 e 60 anos, para além de provirem de casas diferentes, mantêm entre si uma lógica de continuidade, uma vez que têm a mesma autoria, o mesmo título e pressupõem a adoção de um projeto editorial de continuidade, com estruturas semelhantes entre o 50 e o 60 anos. Ou seja, cada par apresenta-se como um produto 
homogéneo, uniforme e, claramente, evidenciando uma lógica de trabalho didático de assinalável semelhança. Por comodidade, designaremos o primeiro par como 5A e 6ำ, e o segundo par como 5으 B 6으.

Assim, no manual 5 A, os textos incluídos são os seguintes:

A Fada Oriana, de Sophia de M. B. Andresen; "Os quatro músicos", de Contos e lendas de Portugal e do mundo, da recolha de João Pedro Mésseder e Isabel Ramalhete; Anne Frank, de Josephine Poole \& Angela Barrett; Uma aventura na Quinta das Lágrimas, de Ana Maria Magalhães e Isabel Alçada; O Clube das chaves mergulha nos Oceanos, de Maria Teresa Maia Gonzalez e Maria do Rosário Pedreira; Fábulas de La Fontaine (vários textos); Canção dos Abraços, de Luísa Ducla Soares; Abelha, de Rosa Lobato Faria; A muIher e a galinha, de Esopo (diversos textos); para além de vários poemas de Eugénio de Andrade, Álvaro Magalhães, Fernando Pessoa, Luísa Ducla Soares, Antero de Quental e Miguel Torga. Podemos encontrar também textos de Manuel António Pina, António Torrado, Joaquim Jorge de Carvalho e Graça Gonçalves.

No mesmo manual para o 6ㅇa ano (6 A), encontramos textos de: Miguel Sousa Tavares, Oscar Wild, J. K. Rowling, Alice Vieira, António Mota, Maria Alberta Menéres, Irmãos Grimm, Daniel Defoe, Ali Babá e os quarenta ladrões, Roald Dahl, Lewis Carroll, António Sérgio, Sophia de M. B. Andresen, Manuel António Pina, Joaquim Jorge de Carvalho e Almeida Garrett.

No outro par de manuais e especificamente para o 5ㅇa ano (5으) estão naturalmente em destaque seis textos de Alice Vieira, outros cinco de Luísa Ducla Soares, Alves Redol, cinco de António Torrado, e outros tantos de Álvaro Magalhães. Mas vemos igualmente, Sempé e Goscinny, seis fábulas de La Fontaine, três de Sophia de M. B. Andresen, vários dos Irmãos Grimm, assim como oito de Contos e lendas de Portugal. Há ainda pre- 
sença firmada autores como Miguel Sousa Tavares, Ana Maria Magalhães e Isabel Alçada; essas últimas com três textos, várias das Fábulas de Esopo, mas ainda Ilse Losa, Maria Alberta Menéres, Manuel António Pina, Cecília Meireles, Miguel Torga, Jorge Sousa Braga, Roald Dahl, Eugénio de Andrade, José Jorge Letria e Manuel Alegre.

No livro de textos para o 60 ano (6으), dos mesmos autores e da mesma editora, podemos encontrar dezasseis textos de António Torrado, outros tantos de Sophia de M. B. Andresen, Gonçalo M. Tavares, Manuel António Pina, cinco dos irmãos Grimm, assim como seis fábulas de La Fontaine, ou Joanne K. Rowling, para além de seis dos Contos populares portugueses. Há ainda presença assídua, Alice Vieira com quatro textos, Ondjaki, Luísa Ducla Soares, Daniel Defoe, António Gedeão, Oscar Wilde, Isabel Allende, Mia Couto, Maria Alberta Menéres, António Gedeão, Pedro Freire Costa, Miguel Torga, Eugénio de Andrade, e vários da recolha de Almeida Garrett (Romanceiro). O aluno encontra também João Manuel Ribeiro e Vinicius de Moraes.

Note-se que, para além desses textos e autores, e cumprindo as instruções programáticas, esses quatro manuais apontam para outras obras e escritores. Dois deles referem, por exemplo: “Apresentamos, de seguida, um conjunto de sugestões de leitura. São algumas das obras indicadas para leitura autónoma no Plano Nacional de Leitura (PNL) para o 60 ano de escolaridade. Boas leituras!" (p. 17). Por essa razão, quando o texto e/ou autor se encontram como leitura aconselhada na lista do PNL, os manuais assinalam a evidência com a etiqueta do PLNL: $L+$.

Como podemos observar, nessa lista figuram inúmeros autores e obras, sendo que alguns são claramente novas sugestões, mas, outros tantos, reduplicações, como: João de Barros, Enid Blyton, Lewis Carroll, Charles Dickens, Maria Teresa Maia Gonzalez, Alexandre Honrado, Álvaro Magalhães, António Mota, Joanne K. Rowling, Mark Twain, Jules 
Verne, Alice Vieira, Luísa Dacosta, José Jorge Letria, Ondjaki, Luísa Ducla Soares, António Torrado ou Alice Vieira.

Os textos que esses manuais incluem devem ser entendidos à luz das prescrições curriculares, mas não podemos afirmar que eles constituem um corpo fechado de sugestões para esses anos de escolaridade do 2 CEB. Isso seria muito redutor e não exprimiria a variedade de textos e de autores que podem constituir leituras significativas e motivantes para essa faixa etária, até porque os alunos realizam leituras fora dessa lista, por indicação dos professores, em consequência de projetos pessoais de leitura, ou do trabalho de acompanhamento da biblioteca da turma e/ou do agrupamento.

O que está em causa nesta reflexão é exatamente a construção (ou não) de um cânone escolar, uma vez que as atividades desenvolvidas pelos professores são, majoritariamente, decalcadas das instruções incluídas nos manuais. Uma observação atenta, por exemplo, aos dois casos citados, permite-nos concluir que eles contêm instruções simples que passam pela identificação das categorias da narrativa, ou no caso dos textos poéticos, de explicações, paráfrases, opiniões, inferências básicas, justificações do uso de pontuação, exercícios de sinonímia, indicação de números de estrofes, levantamento de figuras de estilo, práticas de derivação de palavras, etc.

Em ambos os manuais, as perguntas mais frequentes no capítulo do texto poético são, por exemplo:

- $\quad$ Conta por palavras tuas;

- Qual o tema do poema?

- $\quad$ Escreve o antónimo de...;

- Quem é o autor? 
- $\quad$ Quem é o sujeito poético?

- Qual a mensagem do poema?

- Quantos adjetivos caracterizam o menino?

- $\quad$ Refere uma comparação;

- $\quad$ Explica por palavras tuas;

- Classifica a estrofe;

- $\quad$ Divide as sílabas métricas;

- Junta um prefixo a cada um dos verbos.

Na secção dedicada ao texto narrativo, as questões são, também elas, acessíveis e repetitivas:

- Identifica a personagem;

- $\quad$ Como se comportou a personagem?

- Qual a intenção do autor da fábula?

- Indica um nome comum coletivo;

- $\quad$ Completa a frase;

- Indica um provérbio semelhante ao da história;

- Classifica o narrador;

- Indica sinónimos para as seguintes palavras;

- Indica antónimos para as seguintes palavras;

- Indica um provérbio que conheças;

- Qual a moral desta história? 
- $\quad$ Transcreve expressões do texto;

- Em que espaço se encontra a personagem?

- $\quad$ Explica como é que eles se conheceram?

- $\quad$ Explica as atitudes das personagens;

- $\quad$ Reconta a história aos teus colegas;

- Isola os parágrafos do texto;

- $\quad$ Descobre e classifica os adjetivos nas seguintes frases;

- $\quad$ Muda os seguintes verbos para outro tempo e modo;

- Qual a opinião da personagem?

A nossa primordial intenção ao longo deste artigo não é, como se depreende, debruçarmo-nos sobre aspetos de essência didática intimamente relacionados com as estratégias de leitura ou quanto às atividades desenvolvidas pelos docentes, uma vez que são dados de natureza muito variável e que se subjugam, em grande parte, ao manual com o qual a turma trabalha e que, em alguns casos, é superior a uma dezena de livros diferentes para o mesmo ano letivo.

Ainda assim, esses simples dados permitem-nos concluir que os textos estão, na prática, muito submissos a atividades e a exercícios que visam cumprir os requisitos exigidos pelo Programa de Português: os domínios da gramática, oralidade, leitura e escrita e educação literária. Todavia, essas divisões que o documento curricular prescreve podem originar, como facilmente se observa, uma compartimentação e isolamento no momento da leitura dos textos, e até uma diluição do mesmo em proveito da aquisição de múltiplos conteúdos que o docente tem de obrigatoriamente cumprir. Apesar desse levantamento 
não poder ser exaustivo, pelas razões que expusemos, é certo que muitos dos compêndios textuais para esse ciclo enfermam das mesmas limitações.

\section{Algumas pistas de reorientação das leituras}

Ainda que essa listagem efetuada não nos permita aferir com rigor nem acuidade quais os textos e autores que realmente formam o leitor nesse ciclo de ensino, também o tratamento didático em torno dos textos nos suscita duas questões imediatas.

Alguns deles poderão padecer de determinados desnivelamentos relativos às expetativas desses leitores, como já tivemos oportunidade de aflorar em estudo anterior. É muito provável que alguns destes estejam já seguramente fora do alcance e do interesse dos alunos. As temáticas podem não corresponder cabalmente ao que esperam, mas também as capacidades de leitura e vivências dos alunos são motivos invocados que explicam, por vezes, as razões pelas quais os alunos consideram que os textos estão afastados de si.

Alguns docentes identificam visivelmente esses desajustamentos, mas são sobretudo os alunos que os verbalizam. Já tivemos a oportunidade de referir esse aspeto, uma vez que, por exemplo, no caso das lendas, dos contos populares, alguns manifestam o desinteresse próprio de quem já leu ou de quem considera que as leituras não estão adequadas à sua curiosidade. Outros referem mesmo textos, como a Fada Oriana ou as Fábulas de La Fontaine ou de Esopo, como tendo sido já objeto de leitura no 10 Ciclo (10 CEB). E, de facto, a excelência dos textos de Sophia de M. B. Andresen, as fábulas e os contos populares constituem trunfos de leitura para qualquer professor desse ciclo de ensino, o que faz com que os docentes os convoquem no 1ํㅡㄹ. Mas não são esses os únicos tex- 
tos que se podem identificar como aqueles que emergem recorrentemente no domínio da educação literária.

O mesmo pode suceder com outros textos e autores, uma vez que foram lidos no final do ciclo anterior. É o caso dos contos dos irmãos Grimm, do Robinson Crusoé, do Ali Babá, de vários poemas de Luísa Ducla Soares que, pela sua linguagem, temas e jogos vocabulares têm presença assídua no 1ํㅡㄹ. Essa aparente reduplicação não constitui, só por si, um recurso negativo, desde que não institua uma solução didática generalizada e iterativa ao longo dos dois anos que compõem esse ciclo. Para muitos professores, essas opções justificam-se à luz da essência desse ciclo de ensino, cujo estatuto híbrido e por vezes pouco preciso, tem alguma dificuldade em se afirmar isoladamente entre os dois ciclos com os quais confinam. Talvez seja também por essa razão que, com frequência, se considera que esses dois anos de escolaridade são uma ponte demasiado estreita entre o 1ำ e o 3 ํㅡㄹ Ciclo do ensino básico português.

Parece certo, pois, que os manuais plasmam as indicações do programa de modo muito objetivo, uma vez que reproduzem fielmente as instruções, não apenas quanto aos textos e autores, mas mesmo quanto ao número de textos para leitura. Em alguns casos, ultrapassam até esse número, facto que poderá ter diferentes interpretações. Não podemos aferir, obviamente, quais são as sugestões finais que chegam às mãos dos alunos, para além das que o manual encerra. Não é possível definir com rigor esses indicadores, pela simples razão de que eles entram no âmbito das práticas docentes em contexto de aula. Não há ainda estudos suficientes que permitam avaliar com rigor quais são realmente os textos disponibilizados aos alunos, atendendo à multiplicidade de fatores que concorrem para as seleções de cada professor. 
Porém, e de acordo não só com a investigação produzida nos últimos anos no domínio dos manuais escolares em Portugal, como também com o conhecimento direto das práticas em sala de aula, estamos em crer que a expressiva maioria dos docentes usa o manual como fonte primacial de textos para leitura obrigatória. Essa convicção nasce de duas ou três evidências. Por um lado, a observação atenta dos manuais em uso permitenos concluir que os textos são similares entre eles, ainda que de distintos autores e casas editoras. Por outro, a gestão letiva muito apertada poderá não permitir aos docentes e alunos uma fuga muito longínqua para além das fronteiras textuais que os manuais circunscrevem. Um outro fator prende-se com as questões relacionadas com o peso e a obrigatoriedade da avaliação dos alunos, as provas finais e demais questões em torno dela. Essas restrições e constrangimentos de calendário não deixam por vezes uma margem de liberdade muito expressiva aos docentes. Nem aos alunos.

Mas serão esses textos suficientes para a formação do leitor? Admitimos que essa observação é muito pertinente e reconhecemos que não existem investigações e trabaIhos de campo suficientes que nos permitam asseverar que uma maior oferta textual poderia representar um maior grau de envolvimento com a atividade de leitura ou, pelo menos, uma possibilidade mais vasta de o aluno encontrar o foco do seu interesse ou uma nova motivação para ela. Será, pois, essencial considerarmos a possibilidade de alargamento desse corpo de leituras destinadas a jovens por vezes ainda tão imaturos no domínio das competências de leitura?

Em estudos anteriores, como é o exemplo de Custódio (2012, p. 101), consideramos que, a par da lista vigente, "há ainda outras sugestões que deveriam, igualmente, colher as preferências de alunos e de professores, (e pais) no momento da seleção". Referíamo-nos a textos que, por vezes, "ficam na penumbra das escolhas infrequentes". 
E, na altura, exemplificamos com autores reconhecidos, e cujos textos vão (muito) ao encontro das expetativas desses leitores, como Jaime Cortesão, José Fanha, Afonso Cruz, Antero de Quental, Manuel Alegre, Juan Ramón Jiménez, Hélia Correia, SaintExupéry, João de Barros, Lewis Carroll, Charles Dickens, Emilio Salgari, entre uma vasta plêiade de textos possíveis. Essas sugestões decorrem não apenas do interesse de alguns textos desses autores, relativamente às diferentes temáticas, mas também à facilidade e adequação das mesmas à faixa etária em causa. Um outro fator relaciona-se com a questão da diversidade, que é sempre louvável e muito bem aceito pelos alunos, uma vez que Ihes permite afastarem-se de textos que já leram. Esse ecletismo contribui, ainda, para que o aluno não encare o manual como um repositório de leituras excessivamente fechado, para além de lhe propiciar leituras novas e distintas, nas quais não pontuam sempre os mesmos autores e textos.

No caminho da adoção da diversidade para esse ciclo, mostramos também (CUSTÓDIO, 2012), por exemplo, que a nossa literatura é muito fértil em excelentes textos, de leitura simples, mas igualmente enriquecedora. De entre uma variedade de textos e de autores capazes de cumprirem essa função supletiva de leitura, citamos os casos de Camilo, Eça, Aquilino, José Gomes Ferreira, Gil Vicente, Trindade Coelho, Raul Brandão, Mário de Sá-Carneiro, Miguel Torga, José Rodrigues Miguéis, Sidónio Muralha, Fernando Namora, Fernanda de Castro, Maria Judite de Carvalho, António Alçada Baptista, António Ramos Rosa, José Gomes Ferreira, Maria Ondina Braga, Vergílio Ferreira, ou outros mais contemporâneos, como Manuel Jorge Marmelo, Mário Cláudio, Mário de Carvalho, Lídia Jorge, Jacinto Lucas Pires ou Valter Hugo Mãe. São os únicos autores que podem figurar como leituras extensivas? Obviamente que não. São apenas uma mão-cheia de sugestões, 
mas que estão muito longe de esgotar as possibilidades de oferta de leitura para esses dois anos do ciclo.

Poderemos considerar que os textos dos manuais não são suficientes para alcançar esse desígnio? A nossa opinião é que não. Não por não serem importantes ou representativos, mas apenas porque não são suficientemente amplos e variados. Cremos que esse é o entendimento generalizado dos docentes, e mesmo das autoras do Programa ou dos manuais, que também parecem estar em consonância com esse princípio. É por esse motivo, por exemplo, que ambos invocam amiúde o PNL, uma vez que há uma clara perceção de que será essa uma das formas de enriquecer e de diversificar o acervo de leituras. Essa preocupação é, aliás, transversal a qualquer um dos ciclos do nosso sistema de ensino.

O que nos falta fazer, pois, para eliminar esses desajustamentos entre os textos que propomos aos alunos e as áreas de interesse de cada um deles? Como tornar as leituras literárias mais atrativas e adequadas a cada leitor? Como evitar as reduplicações de textos e de leituras entre ciclos?

Essas não são questões de rápida e fácil resposta, uma vez que dependem de fatores muito diversos e de contextos de ensino que são, também eles, muito distintos e por vezes irrepetíveis.

Arriscaremos, todavia, adiantar algumas pistas capazes de atenuar estes efeitos. De forma breve, elencaremos apenas nove, sabendo que nenhuma delas esgota as potencialidades didáticas da leitura, nem esvazia as dezenas de outras apostas de que os professores podem lançar mão, pois estamos conscientes de que cada turma tem um perfil próprio e apresenta um desafio singular. 
Uma das primeiras medidas de fácil implementação parece-nos a de auscultar os alunos, em início de ciclo, acerca das leituras efetuadas na etapa anterior de aprendizagem. Essa tarefa é de fácil execução e, oralmente ou por escrito, o docente terá uma visão de conjunto mais apurada dos textos e dos autores que os alunos já leram, os de que mais gostaram, os que não colheram as suas maiores preferências ou, simplesmente, os de que se lembram. Essa prospeção inicial terá a vantagem de evitar reduplicações desnecessárias relativamente ao ciclo anterior. Não esqueçamos que alguns dos textos que constam do Programa do 2 CEB já foram objeto de leitura no ciclo anterior, exatamente porque os docentes entenderam que eles estavam ajustados aos gostos e à maturidade do leitor, ou então por serem de excelente qualidade e da preferência dos alunos. É o caso, como vimos, de alguns textos de Sophia de M. B. Andresen.

Uma segunda sugestão é, pois, atender às indicações adicionais que os manuais oferecem e às remissões que fazem para as listas do PNL. Como é consensual entre os docentes, os manuais não podem, por razões orgânicas e estruturais, incluir um número muito elevado de textos para além dos consignados no Programa, pelo que convém aos professores olhar cada vez mais para além das fronteiras dos manuais e procurar, fora das suas páginas, as leituras que os alunos devem realizar.

Uma terceira possibilidade - muito frequente, aliás, nesse ciclo - é a de desenvolver projetos de leitura coletiva e individual com os alunos, possibilitando um incremento da leitura autónoma, um encontro mais íntimo entre cada leitor e o texto e, consequentemente, uma maior probabilidade de o aluno criar laços mais estreitos com determinados textos e/ou autores, aumentando assim a frequência de leituras. Essa estratégia pode ser articulada com uma quarta: a da biblioteca escolar ou de turma, uma vez que esses círculos de leitura, para além de estimularem o conhecimento de outros textos, condu- 
zem à leitura autónoma e plural. Nessa etapa do desenvolvimento educativo e de cultura do livro no seio dos agrupamentos de escolas, quer os professores bibliotecários, quer as escolas, têm apostado de modo significativo nesse cruzamento de vontades e de sinergias. Trata-se, tão-somente, de conceder mais tempo aos livros e mais destaque à(s) leitu$\mathrm{ra}(\mathrm{s})$.

Uma quinta pista - e que advém das anteriores - vai no sentido de criar nos alunos o hábito de falarem de e sobre os livros. Essa atividade deveria ser instituída com indefetível regularidade, porquanto permite aos alunos expressarem livremente a opinião ou um juízo crítico sobre o que leram, ainda que sejam muito incipientes e não sistemáticos. Todavia, esse hábito fortalece os laços com os livros, os textos, os autores; reforça a capacidade de interpretação do aluno, agiliza a proximidade com os textos de literatura, dessacraliza a leitura sem a banalizar e, sobretudo, confere aos alunos um papel de mediador na leitura, questão que julgamos ser fundamental para a sedimentação das práticas de leitura literária em contexto escolar, e fora dele.

Uma sexta ilação é a de que deveremos estimular, cada vez mais, o conceito de pesquisa, de procura por outros textos. Numa época na qual imperam os mecanismos eletrónicos de busca e em que a informação está cada vez mais acessível, será importante rentabilizar esse dispositivo. Hoje, mais do que nunca, os docentes terão de saber usar as tecnologias de informação, não como um fim em si mesmo, mas como um meio ao serviço da educação. Nesse caso, com o objetivo de ir mais além nos conhecimentos que os alunos têm sobre os textos, na procura de edições, autores, temáticas, géneros, épocas, personagens, espaços, tempos, contextos, etc.

Um sétimo remate vai no sentido de podermos também incentivar a intertextualidade, de sabermos despertar as extraordinárias potencialidades desse mecanismo de 
conhecimento da literatura, uma vez que cada texto se pode abraçar a outro, conduzirnos a análogos, de nos levar pelas palavras, pelos temas, a tantos semelhantes, próximos ou distantes, do nosso ou de outro tempo. Essa é uma opção didática que ainda não está inteiramente explorada e que possibilitará um conhecimento mais alargado de novos autores e textos.

Em oitavo lugar, gostaríamos de destacar também uma conclusão que consideramos tão relevante quanto óbvia: a reformatação dos espaços e dos tempos de leitura. $\mathrm{Na}$ verdade, essa atividade não se pode circunscrever ao tempo da aula; esse confinamento é insuficiente. O desenvolvimento da competência leitora e do gosto pela leitura literária podem começar dentro do espaço da aula, mas jamais terminarão dentro das suas fronteiras. O mesmo se passa com o tempo que se entrega à atividade de leitura. As horas disciplinares de Português são distribuídas por diferentes tarefas, conteúdos e domínios. Nem sempre o da leitura é o mais expressivo ou abundante. Essa escassez terá obrigatoriamente de ser colmatada com a leitura autónoma e intimista, com o diálogo cúmplice que se estabelece entre o leitor e cada texto. Para tal, a leitura terá de conquistar um lugar próprio, por vontade e nunca por imposição. Mas só o aumento da frequência da leitura e a criação de um hábito regular de exercício dessa atividade podem assegurar o seu aperfeiçoamento.

Finalmente, uma nona e última conclusão de entre as muitas que poderíamos aqui catalogar, e talvez uma das mais simples de cumprir, uma vez que não depende diretamente do leitor: a de não instrumentalizarmos a leitura e a de não a tornarmos uma vítima constante da avaliação. A leitura não poderá continuar a ser uma arena didática de constantes incursões avaliativas. De outo modo, ela será sempre associada a uma falsa e 
errónea finalidade: a de que ela existe para avaliar os alunos. A sua existência fica caucionada por aquilo para a qual não foi concebida.

\section{Conclusões breves}

Neste rápido sobrevoo aos textos que os manuais incluem, podemos observar que, na verdade, esses instrumentos de recontextualização pedagógica cumprem a função nuclear para a qual estão destinados, para além de constituírem dispositivos que emulam, com notável grau de fidelidade, as instruções curriculares. Nesses aspetos, esses utensílios de trabalho são muito rigorosos e não fazem desvios às orientações programáticas. Na maior parte dos casos, o que podemos observar é que eles acabam por incluir mais textos dos autores consignados no programa, para além do número mínimo aconseIhado.

Por outro lado, também se conclui que eles tentam fornecer pistas e orientações válidas e contextualizadas no que concerne a outras leituras. Por essa razão, é hoje muito comum - e esses quatro manuais comprovam-no - os autores terem a preocupação de fazer com que a leituras saiam das fronteiras do livro escolar, uma vez que elaboram listas de textos para cada um dos anos que compõem esse ciclo.

Convém assinalar que essa intenção está ao serviço de um bem maior e de um objetivo muito definido, identificado e de grande relevo: o de fazer sugestões de leituras suplementares e de mostrar aos alunos que há uma extensa lista de propostas de leitura sobre as quais poderá recair uma possível escolha, muito mais individual e personalizada. Esses elencos realçam, ainda, o papel e a importância do acervo PNL, ao mesmo tempo 
em que se ergue como um convite à leitura autónoma, à escolha pessoal e, indiretamente, à liberdade que uma vasta biblioteca permite.

Esses trilhos de leitura que os manuais desenham são de assinalável relevância porquanto permitem aos alunos e aos professores encetar outras leituras e conhecer outros textos e autores. $\mathrm{E}$, de entre eles, muitos estão bem adaptados à maturidade do leitor ou, simplesmente, vão ao encontro dos seus gostos e preferências, das temáticas mais motivantes ou, de uma forma mais ou menos explícita, são textos com os quais os alunos mais se identificam, dirimindo e atenuando a questão que alguns professores e alunos assinalam: a do aparente desnivelamento entre os textos e a faixa etária do leitor. Não obstante, e apesar de todos os esforços, alguns dos manuais poderão não cumprir cabalmente o objetivo de diferenciação.

Uma vez que o manual constitui o material de excelência para trabalho do e sobre o texto literário, será importante compreender, pois, o papel dessas listas de textos e sugestões supletivas no âmbito da leitura literária para esse ciclo, uma vez que essa estratégia didática de complementaridade pode contribuir de forma significativa para o chamamento para a leitura e, consequentemente, para a formação desse leitor. Consideramos ainda que, na generalidade, os textos prescritos no Programa e, posteriormente, vertidos nos manuais não serão talvez suficientes para levar a cabo a complexa missão de formar um leitor. Não por questões de qualidade ou de quantidade, mas por razões de diversidade.

De facto, consideramos que é imperioso abrir substancialmente o leque de oferta de leitura: outros autores, novos textos, temáticas distintas, géneros diversos, textos de diferentes épocas e períodos, com assinalável enfoque nos contemporâneos, talvez os mais próximos dos alunos. Mas não exclusivamente. 
O texto literário não existe nem sobrevive em função da avaliação e não poderá continuar por muito mais tempo a cumprir alguns objetivos que the queremos impor, ainda que com generosas intenções. Essa questão, muito sensível e de alguma complexidade, terá de ser encarada com seriedade e dureza, sob pena de os alunos continuarem a entender que o texto literário existe sobretudo para testar o desenvolvimento das suas competências nos diferentes domínios e atestar a aquisição de conteúdos e a aplicação de conhecimentos. Por muito que tenhamos progredido nos últimos anos e estejamos a caminhar disruptivamente num sentido diferente, ainda há um árduo caminho a percorrer.

Pelo exposto consideramos, pois, que há algumas medidas e opções de trabalho na esfera das práticas docentes que poderão facilitar não apenas o contacto dos alunos com os textos literários, mas também fomentar o encontro pessoal entre os textos e os leitores. Ora, nessa dinâmica letiva, convém concluir que é imperioso evitar desajustamentos no tocante às leituras e reduplicações desnecessárias, ainda que fortuitas.

Na verdade, os desajustamentos podem ser colmatados com a aferição mais pormenorizada do perfil da turma e dos alunos, evitando disponibilizar textos que estão já, pelos seus temas ou grau de dificuldade, aquém das possibilidades interpretativas dos alunos. Por outro lado, as reduplicações também se podem facilmente evitar, pela consulta e auscultação atempada sobre as leituras já efetuadas no ciclo anterior. Desse modo, e conjugando essas duas diretivas, será possível ir aperfeiçoando o trabalho em torno da educação literária dos alunos, propondo, cada vez mais, uma lista mais ampla de textos e de autores e, de forma progressiva, tornando a leitura uma atividade mais independente, menos escolarizada e, assim, mais próxima da esfera dos interesses e sobretudo das rotinas de cada leitor. 


\section{Referências}

AZEVEDO, Fernando; BALÇA, Ângela. Leitura e educação literária. Lisboa: Pactor, 2016.

BERNARDES, José Cardoso; RUI, Afonso Mateus. Literatura e ensino do português. Lisboa: Fundação Francisco Manuel dos Santos, 2013.

BUESCU, Helena; CORTEZ, António Carlos. Presente e futuro: a urgência da literatura. Lisboa: Centro Cultural de Belém, 2015.

BUESCU, Helena et al. Programa e metas curriculares do ensino básico. Lisboa: Ministério da Educação, 2015.

CABRAL, M. Como analisar manuais escolares. Lisboa: Texto Editores, 2005.

CASTRO, Rui Vieira et al. Manuais escolares: estatuto, funções, história. Braga: Universidade do Minho, 1999.

CUSTÓDIO, Pedro Balaus. Experiências significativas no 2으 CEB - Representatividade e qualidade dos textos literários. Revista Exedra, Coimbra, 2012. In Português - Investigação e Ensino. Exedra - Número Temático.

. Considerações sobre o uso de Antologias de textos literários no Ensino

Básico. DEDiCA. Revista de Educação e Humanidades, Universidade de Granada - Espanha, n. 12 , p. 53-68, 2017a.

Um pouco mais de sol - eu era brasa, / um pouco mais de azul - eu era além. Da nascente à foz: textos de autores grandes para pequenos leitores. Revista de Educação e Humanidades, Universidade de Granada - Espanha, n. 11, p. 83-100, 2017b.

Entre Cila e Caríbdis Intransitividades da leitura literária no 2ํ Ciclo do Ensino Básico. In: VII SIELP, 2018, Universidade do Minho. Atas do VII SIELP [...]. Braga: (no prelo), 2018.

DIONÍSIO, Maria de Lurdes. A construção escolar de comunidades de leitores. Coimbra: Livraria Almedina, 2000.

. Literatura, leitura e escola. Uma hipótese de trabalho para a construção do leitor cosmopolita. In: PAIVA, A. et al. Leituras literárias: discursos transitivos. Belo Horizonte: Ceale, 2005.

MARTINS, Moisés de Lemos. Lusofonia e interculturalidade: promessa e travessia. Famalicão: Edições Húmus, 2015. 
MORENO, Víctor. La formación literaria. Salamanca-Espanha: Fundación Germán Sánchez Ruipérez: Lectyo, 2015.

NÚÑEZ SABARÍS, Xaquín et al. Horizontes científicos y planificación académica em la didática de lenguas y literaturas. Famalicão: Edições Húmus, 2015.

PINTO, Maria da Graça Castro. Nos bastidores da iniciação à entrada no mundo da escrita. Porto: CLUP, 2017.

ROIG RECHOU, B. A. Educação literária e literatura infanto-juvenil. Porto: Tropelias \& Companhia, 2013.

ROSENBLATT, L. M. The reader, the text, the poem: the transactional theory of the literary work. Carbondale: Southern Illinois University Press, 1994.

SILVA, Vítor Manuel Aguiar e. O texto literário e o ensino da língua materna. In: As humanidades, os estudos culturais, o ensino da literatura e a política da língua portuguesa. Coimbra: Almedina, 2010. p. 181-190.

SOUSA, Otília Costa. Textos e contextos: leitura, escrita e cultura letrada. Lisboa: Editora Media XXI, 2015.

Recebido em 24 de maio de 2019.

Aceite em 30de outubro de 2019. 